\title{
The effect of self-efficacy and coping strategies on treatment motivation of individuals in the substance addiction group work process
}

\author{
Tugba Gorgulu10
}

${ }^{1}$ Visit.Asst.Prof., University of Rochester, Department of Psychiatry, ${ }^{2}$ Dr.Ogr.U., Istinye University, Department of Social Work, Istanbul - Turkey

\begin{abstract}
Objective: Substance use behavior is increasing in Turkey, as is the importance of substance use treatment and rehabilitation programs. Substance users' compliance and treatment motivation are crucial for the effectiveness of treatment and rehabilitation programs. Accordingly, the purpose of this study is to examine the relationship between psychosocial variables and treatment motivation and to determine the effects of psychosocial variables, self-efficacy, and coping strategies on treatment motivation.

Method: The study was conducted among 336 substance users taking part in a Cigarette, Alcohol and Drug Addiction Treatment Program (SAMBA) group program.

Results: A significant difference in treatment motivation was found according to the individual's age, educational status, and income level, duration of substance use and number of substances used, family problems, and psychiatric comorbidity. In addition, the most important predictive variables for treatment motivation are the individual's income level, the presence of children, family problems, and coping strategies.

Conclusion: Cognitive and behavioral studies should be undertaken to strengthen social support mechanisms, to increase the supportive participation of family members, and to develop coping strategies as well as motivational techniques in order to increase the individuals' compliance and motivation.
\end{abstract}

Keywords: Addiction, coping, self-efficacy, substance abuse, treatment motivation.

\section{INTRODUCTION}

As in other parts of the world, substance abuse behavior in Turkey has reached dramatic levels. According to some data, the use of intoxicants including drugs of high purity has increased by almost $100 \%$ between 2012-2014 (1,2). In addition to being a significant public health issue in itself, substance use is also correlated with a number of biopsychosocial problems such as depression, anxiety, mental and medical issues, self-harm, and suicide (3-5). Therefore, substance use is at the same time an important public health issue requiring prevention and causes a series of other relevant public health issues that need to be addressed.

Intervene to the dramatic increase in substance use behavior and improving preventative measures are

How to cite this article: Gorgulu T. The Effect of Self-efficacy and Coping Strategies on Treatment Motivation of Individuals in the Substance Addiction Group Work Process. Dusunen Adam The Journal of Psychiatry and Neurological Sciences 2019;32:33-42.

Correspondence: Tugba Gorgulu, 'Visit.Asst.Prof., University of Rochester, Department of Psychiatry, ${ }^{2}$ Dr.Ogr.U., Istinye University, Department of Social Work, Istanbul - Turkey

Phone: +90 8502836000 E-mail:Tugba_Gorgulu@URMC.Rochester.edu

Received: June 11, 2018; Revised: July 05, 2018; Accepted: September 26, 2018 
critical to prevent the numerous biopsychosocial problems that cause and accompany substance use. Therefore, research on substance use treatment and rehabilitation programs and their implementation as well as an interest in the topic as a whole is growing day by day. Doubtless, the effectiveness of therapy is determined by cooperation with patients, their positive attitude to therapy, and their collaboration with the healthcare professional. Motivation is defined as people's intention to change their behavior (6). Lack of motivation in a patient can cause them to quit therapy or find it hard to complete their course of treatment, leading to relapse or a number of other problems emerging during therapy (7). Thus, the strength of a person's motivation is proportional to the effectiveness of treatment and rehabilitation programs. Particularly internal motivational factors (desire to quit, urge to succeed, determination) are seen to be the most important factors to achieve abstinence. However, certain external motivational factors (spouse, children, financial needs...) undeniably also play a role in quitting substance use (8).

Many addicts are reluctant to participate in treatment and rehabilitation programs. A critical motivational power for a person to decide quitting substance use and continuing treatment to completion is self-efficacy, defined as an individual's belief that he or she has a sufficient capacity to begin and complete an achievement in their social environment and reach the expected outcome $(9,10)$. Particularly in individuals with low self-efficacy who consider themselves inadequate to reach abstinence, treatment compliance and motivation are reduced, and in this state, the participation of addicts in treatment and rehabilitation programs and their adherence with the treatment are affected negatively. Some studies show that the selfefficacy factor is important in quitting drinking and substance use. While this is a short-term effect, the individual's self-efficacy in the long term is significantly decreased (11). The enhancement of a person's selfefficacy is an important factor for their motivation to take up and adhere to treatment (12).

Another positive factor affecting a person's ability to initiate and adhere with treatment is their capacity to cope with negative situations or stress factors. Studies show that most addicts have experienced psychosocial problems and repeatedly tried to abstain but felt that they were too weak to quit their habit (13). This phenomenon indubitably weakens coping capacities and is detrimental to the subject's motivation. Studies indicate that an increase in an individual's coping capacity leads to an increase in their efficacy to become abstinent (14). On the other hand, coping capacity is not only a motivational power regarding drug abstinence but at the same time reduces the relapse risk (15).

In the light of this information, for a successful treatment it is important to establish supportive psychological factors for drug users to start and complete addiction treatment and rehabilitation programs successfully and to eliminate risk factors. Thus the aim of the study is to assess the relation between various psychosocial variables and treatment motivation in addicts on therapeutic probation for illegal substance use in the sense of article 191 Turkish Penal Code participating continuously in the "Cigarette, Alcohol and Drug Addiction Treatment Program" (SAMBA) (16) group program and to establish the effect of psychosocial variables, self-efficacy, and coping strategies on treatment motivation.

\section{METHOD}

This study was undertaken with individuals that had been referred to the Probation Directorate in Ankara after being sentenced for the consumption of illegal substances under article 191 of the Turkish Penal Code. The study sample consisted of 336 male participants who were part of a Cigarette, Alcohol, and Substance Addiction (SAMBA) (16) group program and had completed at least two sessions of the program. The participants were recruited from among the male addicts using random sample technique.

Sociodemographic Data Form: Prepared by the researcher, this form includes entries collecting psychosocial data related to substance use behavior and risk factors as well as demographic questions about age, gender, and marital status.

Treatment Motivation Questionnaire (TMQ): TMQ was, developed by Ryan et al. (17) and it is a 5-point Likert-type scale with 26 items. This scale, developed to assess reasons to initiate and continue treatment, includes 4 subscales. The "external motivation" subscale consists of 4 items measuring an addict's external factors, pressure or requests to start and go on with treatment. The "internal motivation" subscale with 11 items assesses internal factors, such as guilt or shame, pushing the addict towards initiation of treatment and retention. The "confidence in treatment" subscale uses 5 items to measure expectations regarding the course of therapy. Finally, the "interpersonal help-seeking" 
subscale evaluates the addicts' motivation to share their problems and treatment expectations with others. According to the psychometric evaluation, the internal consistency coefficients for the instrument range between 0.70 and 0.98 and the construct validity was found to be at an acceptable level. The adaptation of the scale to Turkish was worked out in a study by Evren et al. (18). They found internal consistency coefficients for the subscales between 0.42 and 0.91 , and the item correlations were significant.

The General Self-Efficacy Scale-Turkish Form: The original form, was developed by Sherer et al. (19) and consists of 23 items measuring people's belief to be able to cope with stressful and difficult life events. It is divided into 2 factors, "social self-efficacy," measured with 6 items, and "general self-efficacy," assessed with 17 items. The construct validity was assessed with 6 measures, and a sufficient correlation coefficient was found. However, the authors recommended using the 17 -item general self-efficacy subscale alone. In several studies, the 17-item general self-efficacy subscale was administered (20). A validity and reliability study for the scale in Turkish was carried out by Yildirim et al. (21), finding an internal consistency coefficient of 0.80 and a testretest reliability of 0.69 . In addition, correlations with the Self-esteem Scale, Learned Resourcefulness Scale, Locus of Control Shedule and Beck Depression Inventory were $0.48,0.57,-0.30$, and -0.49 , respectively, and the results were significant.

\section{Coping Strategies Questionnaire Brief Form (Brief}

COPE): The original questionnaire was developed by Carver et al. (22) and consists of 60 items in 15 subscales. As this form was too long and did not show enough psychometric features, it was again Carver (23) to develop a Coping Strategies Questionnaire brief form. This version consists of 28 items measuring problem- and emotion-centered coping strategies. The scale consists of 14 subscales with 2 items each. These subscales are "active coping," "planning," "positive reframing," "acceptance," "humor," "religion," "use of emotional support," "use of instrumental support," "self-distraction," denial," "venting," "substance use," "behavioral disengagement," and "self-blame." Each item is scored from 1 ("I haven't been doing this at all") to 4 ("I'm doing this a lot"), resulting in a total score between 28 and 112. For each subscale, a high score indicates a frequent use of the respective coping strategy. The psychometric evaluation of the scale found internal consistency coefficients between 0.50 and 0.90 . The instrument was adapted to Turkish by Tuna (24), who found a total correlation coefficient for the scale between 0.36 and 0.91 and an internal consistency coefficient between 0.26 und 0.91 .

\section{Procedure}

Before beginning the tests, it is briefly explained the general aim of the study to the participants. Individuals who agreed to participate was received the scales and an informed consent form. After beginning the tests, participants were informed that they could withdraw from the study if they were uneasy about the questions or they could request psychological support from the researchers. To avoid fatigue as a confounding factor, the scales were administered to each participant in a different order. In addition, for the question regarding the presence of a psychiatric disorder, a diagnosis by a psychiatrist was requested. Before beginning the study, the required permissions from the researchers who had adapted the measures to Turkish were obtained. Furthermore, legally required permissions were received from the Ministry of Justice's Directorate General of Prisons and Detention Facilities and from the ethics committee for non-interventional clinical research of Hacettepe University.

\section{Statistical Analysis}

To test the study data for normal distribution, all scores were converted to $\mathrm{z}$ scores, confirming normal distribution. To assess the differences between psychological variables and treatment motivation, independent-samples t-test and ANOVA were used, and to find variables predicting treatment motivation, hierarchical multiple regression analysis was carried out. Before doing hierarchical multiple regression analysis, Pearson Product-Moment Correlation was calculated to determine multicollinearity between variables. All statistical analyses were performed using SPSS 20 (IBM).

\section{RESULTS}

This section first provides data about the sociodemographic and psychosocial characteristics 336 male participants who were enrolled in a SAMBA (16) group program on account of substance abuse. Secondly, the differences between participants' TMQ total scores according to psychosocial variables and finally the results of a hierarchical multiple regression analysis revealing predictive variables for the participants' treatment motivation are given. 


\section{Information About Participants' Sociodemographic Characteristics}

The average age of the participants in the sample was 30.83 years, $39.5 \%$ were middle school graduates, and $60.2 \%$ were unmarried. While $69.4 \%$ were in regular employment, $30.0 \%$ had been long-term unemployed. The monthly income was between 1,700 and 2.700 TL for $32.6 \%$ of the participants, while $5.3 \%$ had no income. Substance use had started before the age of 18 years in $48.7 \%$ of cases, lasted for more than 24 months in $50.7 \%$ of participants, and $53.4 \%$ used more than one substance. The most used substance was marijuana with $81.31 \%$, while $32.5 \%$ used ecstasy, $41.3 \%$ crack or cocaine, $23.4 \%$ alcohol, and $20.5 \%$ heroin. In $70.3 \%$ of participants, it was understood that substance use behavior was present in their families or among their friends. Self-harm behavior was reported by $37.7 \%$ of participants, while $15.7 \%$ had attempted suicide. Of the attempted suicide cases, $43.3 \%$ had swallowed drugs, while $25.0 \%$ had used methods like cutting themselves (Tables 1 and 2).

\section{Results of Intergroup Comparison for Participants' Treatment Motivation}

To assess the differences in participants' treatment motivations according to various psychosocial variables, independent-sample t-test and ANOVA were used in this study (Table 2). First, ANOVA was used to establish if there was a significant difference between participants' treatment motivations according to their age. The analysis resulted in a significant correlation between the two variables $(F[4-307]=2.65, p=0.05)$. Comparing groups using Tukey test, the mean total TMQ scores for individuals in the age group 32-37 years were significantly higher than in the age group $38-45$ years (95\% CI 1.67, 27.53).

A significant correlation was also found between mean total TMQ score and educational status (F[4$324]=2.98, p=0.05$ ). According to Tukey test results, the mean total TMQ scores for individuals graduating from middle school were significantly higher than for participants with a university degree (95 CI\% 0.19 , 24.61).

Another difference regards the participants' monthly income. Treatment motivation of individuals with a monthly income between 400 and $1.000 \mathrm{TL}$ was higher than in the group with a monthly income of $2,800 \mathrm{TL}$ and above (95\% CI 0.14, 31.08), the difference was statistically significant $(F[5-297]=2.20, p=0.05)$.

There was also a significant correlation between duration of substance use and treatment motivation
Table 1: Descriptive statistics regarding some psychosocial variables of the participants $(n=336)$

Variables

n

Marital status

Single 60.2

Married

203

32

Divorced

108

7.4

Regular employment

25

69.4

Criminal record

234

50.7

Self-harm behavior

171

37.7

Suicide attempt

127

15.7

Method of suicide attempt

Cutting
Taking drugs
Hanging
Jirearm
Jumping from a height

53

ubstance use in the family

Age at first use

Below 18 years

48.7

Above 18 years

43.9

Type of substance*

$\begin{array}{lcc}\text { Alcohol } & 79 & 23.4 \\ \text { Marijuana } & 274 & 81.3 \\ \text { Ecstasy } & 106 & 31.5 \\ \text { Heroin } & 69 & 20.5 \\ \text { Cocaine } & 63 & 18.7 \\ \text { Crack } & 76 & 22.6 \\ \text { Solvents } & 32 & 9.5 \\ \text { Substances like LSD-GHB } & 18 & 5.3\end{array}$

*All participants specified the type of substance used. Each participant could indicate more than one type of substance. In Table 1, $\mathrm{n}$ (\%) represents the proportion between the different types of substances.

$(\mathrm{F}[2-263]=3.42, \mathrm{p}=0.05)$, and according to intergroup comparison by Tukey test, motivation in individuals with more than two years of substance use history was higher than among those with less than one year of substance use (\%95 CI, 0.13, 15.23). Another variable affecting treatment motivation was the number of substances used. Treatment motivation was higher in multiple substance users (Mean $=84.73 ; \mathrm{SD}=22.03$ ) than in single substance users (Mean $=77.65 ; \mathrm{SD}=20.70$ ) $(\mathrm{t}[325]=2.99, \mathrm{p}=0.003)$.

Another relevant correlation was seen between TMQ and drug-related family problems $(\mathrm{F}[4-319]=9.98$, $\mathrm{p}=0.05)$. Comparing between groups, treatment motivation was higher in individuals experiencing drug use-related family problems than in those who did not have family problems for the same reason. 
Table 2: Comparing severity of motivation according to the groups

\begin{tabular}{|c|c|c|c|c|c|c|}
\hline Psychosocial variable & $\mathbf{n}$ & $\%$ & Mean & SD & $\mathbf{F} / \mathbf{t}$ & Post-hoc \\
\hline \multicolumn{7}{|l|}{ Age } \\
\hline $18-24^{a}$ & 73 & 18.7 & 81.43 & 20.87 & $2.65^{* *}$ & $c>d$ \\
\hline $25-31^{b}$ & 124 & 31.7 & 79.58 & 21.89 & & \\
\hline $32-38^{c}$ & 81 & 20.7 & 85.56 & 20.31 & & \\
\hline $39-45^{d}$ & 64 & 14.4 & 70.96 & 23.42 & & \\
\hline $46-52^{e}$ & 26 & 6.6 & 84.00 & 20.11 & & \\
\hline 53 and abovef & 23 & 5.9 & 80.96 & 21.54 & & \\
\hline \multicolumn{7}{|l|}{ Education level } \\
\hline Literate $^{a}$ & 14 & 4.2 & 71.07 & 25.13 & $2.98^{* * *}$ & $c>e$ \\
\hline Primary school ${ }^{\mathrm{b}}$ & 69 & 20.5 & 82.66 & 22.05 & & \\
\hline Middle schoolc & 133 & 39.5 & 84.25 & 21.05 & & \\
\hline High schoold $^{d}$ & 90 & 26.7 & 79.68 & 21.88 & & \\
\hline Universitye & 30 & 8.9 & 71.85 & 17.07 & & \\
\hline \multicolumn{7}{|l|}{ Monthly income } \\
\hline No income $e^{a}$ & 18 & 5.3 & 86.55 & 23.97 & $2.22^{*}$ & $b>e$ \\
\hline $400-1000 \mathrm{TL}^{\mathrm{b}}$ & 21 & 6.5 & 89.33 & 17.29 & & \\
\hline $1100-1600^{c}$ & 80 & 23.7 & 82.36 & 20.29 & & \\
\hline $1700-2700^{d}$ & 108 & 32.0 & 81.71 & 21.54 & & \\
\hline $2800-3700^{e}$ & 40 & 11.9 & 73.71 & 22.56 & & \\
\hline 3800 TL and above & 41 & 12.5 & 76.39 & 23.69 & & \\
\hline \multicolumn{7}{|l|}{ Duration of substance use } \\
\hline $0-12$ months $^{\mathrm{a}}$ & 68 & 20.5 & 76.94 & 22.60 & $3.42^{*}$ & $c>a$ \\
\hline $13-24$ months $^{b}$ & 31 & 9.2 & 79.09 & 22.22 & & \\
\hline 25 months and above ${ }^{c}$ & 171 & 50.7 & 84.62 & 20.83 & & \\
\hline \multicolumn{7}{|l|}{ Number of substances used } \\
\hline One & 180 & 53.4 & 77.65 & 20.70 & $2.99^{* *}$ & \\
\hline More than one & 154 & 45.7 & 84.72 & 22.02 & & \\
\hline \multicolumn{7}{|c|}{ Family problems due to substance use } \\
\hline Very often & 77 & 23.1 & 92.33 & 19.62 & $9.98^{* * *}$ & \\
\hline Rarely & 120 & 35.6 & 81.34 & 21.40 & & \\
\hline None & 131 & 389 & 74.39 & 19.04 & & \\
\hline Psychiatric diagnosis & 49 & 14.9 & 88.39 & 21.41 & $2.59^{* *}$ & \\
\hline
\end{tabular}

${ }^{*} \mathrm{p}<0.05,{ }^{* *} \mathrm{p}<0.01,{ }^{* * *} \mathrm{p}<0.001$

Note: $*^{* * * * * *}, 1 \%, 5 \%$ and $10 \%$ level, respectively, does not refer to significance levels.

$\mathrm{n}=$ Sample size; $\mathrm{SD}=$ Standard deviation; $\mathrm{F}=\mathrm{F}$ value, $\mathrm{T}=\mathrm{t}$-test value; Post-hoc=Tukey Test value

Finally, it was seen that the presence of a psychiatric disorder is an important variable for treatment motivation. Treatment motivation in individuals with an additional psychiatric diagnosis other than substance use (Mean=88.39, $\mathrm{SD}=21.41$ ) was significantly higher than in participants with no other psychiatric diagnosis (Mean=79.73; $\mathrm{SD}=21.35)$.

Results of Regression Analysis for Variables Predicting Treatment Motivation

In order to identify predictive variables for treatment motivation, hierarchical multiple regression analysis was carried out. All details of the model can be seen in Table 3. For the first model, psychosocial variables related with substance use were added, for the second model the General Self-Efficacy Scale, and finally, for the third model the total Coping Strategies Questionnaire Brief Form scores. According to the analysis, model 3 is statistically significant: With $R^{2}=0.227, \mathrm{~F}(10-177)=5.195, \mathrm{p}<0.001$, the adjusted $R^{2}=0.183$ and the proportion of variance explained is $22.7 \%$. The results indicate that the best predictive variables for treatment motivation are the existence of a monthly income, the presence of at least one child, 
Table 3: Results of hierarchical multiple regression analysis for variables predicting the total TMQ score

\begin{tabular}{|c|c|c|c|c|c|c|}
\hline \multirow{2}{*}{$\begin{array}{l}\text { Treatment motivation } \\
\text { Variablesa }\end{array}$} & \multicolumn{2}{|c|}{ Model 1} & \multicolumn{2}{|c|}{ Model 2} & \multicolumn{2}{|c|}{ Model 3} \\
\hline & B & $\boldsymbol{\beta}$ & B & $\beta$ & B & $\beta$ \\
\hline Continuous & \multicolumn{2}{|c|}{$101.03^{* * *}$} & \multicolumn{2}{|c|}{$111.40^{* * *}$} & \multicolumn{2}{|c|}{$83.78^{* * *}$} \\
\hline A & -0.05 & -0.01 & -0.09 & -0.03 & -0.08 & -0.03 \\
\hline B & $-0.00^{*}$ & -0.14 & -0.00 & $-0.3^{*}$ & $-0.00^{* *}$ & -0.12 \\
\hline C & $-9.7^{* *}$ & -0.19 & -9.44 & $-0.19^{* *}$ & $-9.37^{* * *}$ & -0.19 \\
\hline D & 2.24 & 0.05 & 2.21 & 0.05 & 2.31 & 0.05 \\
\hline $\mathbf{E}$ & 1.41 & 0.06 & 1.29 & 0.05 & 2.09 & 0.08 \\
\hline $\mathbf{F}$ & 0.20 & 0.00 & -0.14 & -0.00 & -1.46 & -0.03 \\
\hline G & $-709 * * *$ & -0.30 & -7.78 & $-0.29^{* * *}$ & $-5.44^{* *}$ & -0.21 \\
\hline H & -4.1 & -0.07 & -4.01 & -0.07 & -4.22 & -0.07 \\
\hline I & & & -0.175 & -0.07 & -0.17 & -0.07 \\
\hline \multicolumn{5}{|l|}{ J } & $0.32^{* * *}$ & 0.26 \\
\hline $\mathrm{R}^{2}$ & \multicolumn{2}{|c|}{0.167} & \multicolumn{2}{|c|}{0.171} & \multicolumn{2}{|c|}{0.227} \\
\hline $\mathrm{F}$ & \multicolumn{2}{|c|}{$4.485^{* * *}$} & \multicolumn{2}{|c|}{$4.080^{* * *}$} & \multicolumn{2}{|c|}{$5.186^{* * *}$} \\
\hline$\Delta \mathrm{R}^{2}$ & \multicolumn{2}{|c|}{0.137} & \multicolumn{2}{|c|}{0.004} & \multicolumn{2}{|c|}{0.056} \\
\hline$\Delta \mathrm{F}$ & \multicolumn{2}{|c|}{$4.485^{* * *}$} & \multicolumn{2}{|c|}{0.868} & \multicolumn{2}{|c|}{$12.726^{* * *}$} \\
\hline
\end{tabular}

$\mathrm{n}=302,{ }^{*} \mathrm{p}<0.05,{ }^{* *} \mathrm{p}<0.01,{ }^{* * *} \mathrm{p}<0.001$

Note: ${ }^{* * *}, * * * 1 \%, 5 \%$ and $10 \%$ level, resp., does not refer to significance levels.

$F=F$ value; $\Delta F=C$ hange in $F ; R^{2}=R$ square; $\Delta R^{2}=$ Change in $R$ square; $B=$ Regression coefficient $\beta=$ Standard coefficient

Definition of variables: A. Age: 18-24, 45-31, 32-38, 39-45, 46-52, 53 and above (5 categories), B. Income: No income, 400-1000 TL, 1100-1600, 1700-2700 and 2800-3700

TL (5 categories), C. Existence of children: yes or no (2 categories), D. Age at beginning of substance use: 12-17, 18-24 and 25 and above ( 3 categories), E. Duration of substance use: 0-12, 13-24 and 25 months and above (3 categories), F: Number of substances used: 1 or more than 1 (2 categories), G. Family problems due to substance use: Yes or No (2 categories), H. Psychiatric diagnosis: Yes or No (2 categories). I. General Self-efficacy Scale total score, J. Coping Strategies Questionnaire total score.

Model 1: $A+B+C+D+E+F+G+H ;$ Model 2: $A+B+C+D+E+F+G+H+l ;$ Model 3: $A+B+C+D+E+F+G+H+I+J$

experiencing drug use-related family problems, and coping strategies.

\section{DISCUSSION}

This study found that the most important variables affecting treatment motivation were the individual's monthly income, having at least one child, experiencing substance use-related family problems, and coping strategies. While most substance user want to quit most of the time, it takes time to make the decision and implement it. Thus, to decide quitting and getting into action, it is important for substance user to believe in the capability to abstain and to possess sufficiently strong coping skills. Studies have shown that with stronger coping skills, the person's treatment compliance and motivation increase, leading to a positive effect on participation and continuation of treatment. In particular, psychosocial programs aimed at strengthening coping skills in the treatment of addiction raise improve the patient's internal motivation (14). Therefore, in order to increase the treatment motivation in substance users and improve compliance with therapy, it can be suggested that in addition to motivational interviewing techniques, cognitive and behavioral interventions strengthening coping strategies and skills should be applied.

Another important factors influencing treatment motivation are if the individual has experienced family problems due to substance use and if they have at least one child. While this study doubtlessly could not establish if the family problems were related to substance use, it is thought that problems in the family due to substance use can trigger an increased awareness of the relation between drug use and family problems. In addition, the existence of a child might increase a person's sense of responsibility and make them assess their substance use behavior and decide to change it. However much internal motivation may be crucial in changing the drug habit, social factors affecting external motivation, such as family and friends, also play a role in reinforcing the patient's treatment compliance and motivation $(25,26)$. At this point, it is assumed that family pressure affects the person's external motivation and thus increases treatment motivation. While some studies argued that peer pressure is more effective than family pressure, especially in the case of adolescents, a number of studies also demonstrate that family pressure is a relevant social mechanism 
influencing a person's treatment motivation (27). Thus it is assumed that in order to increase a patient's treatment motivation and thereby improve their compliance, it may be useful to work with family members and ask for their support in the process.

Another factor is the sense of self-efficacy, being an expression of treatment motivation and a person's belief in their ability to quit substance use. Studies show that a substance user's low self-efficacy may trigger negative beliefs, affecting treatment adherence and motivation negatively (28). However, some studies indicate that selfefficacy may be more effective in short-term substance users, while long-term users' self-efficacy can be significantly reduced (11). The study confirmed that selfefficacy is not a significant predictor for treatment motivation. The reason for this result may be the composition of the participants' drug-related characteristics. In fact, almost half of our participants had been using drugs for more than 2 years and again half of them were using more than one substance. This may have affected the sense of self-efficacy negatively, which otherwise could have been an important push factor.

This study found that the substance users in the sample had a low level of education and income, and the great majority had attempted suicide in the past. It is known that substance use behavior, a significant public health issue, is related with numerous problems. We also know that in these individuals, particularly their low educational level and the drug-related inability to fulfill basic responsibilities in school or at work are preparing the ground for social problems such as poverty (29). In a vicious circle, these problems may lead to relapse. Therefore, individuals have to cope not only with the substance use but at the same time with certain social issues such as educational problems and poverty. Evidently, policies are needed to solve these issues. On the other hand, the high rate of suicide attempts in these subjects is a significant risk factor for completed suicide. Actually, suicide rates in substance users are higher than in other groups $(4,30)$. Even though there is no conclusive information about the direction between the two variables, it will be advantageous for the prevention of self-harm and suicide to prevent substance use behavior. This suggests that, in addition to drug prevention programs, in education and the planning of macro interventions, an increase of counseling about drug use in schools, and the offer of treatment and rehabilitation for children and adolescents who have been identified as drug users are necessary.

This study has found a significant correlation between age groups and treatment motivation, which was greater among the 25- to 35-year-olds than among the individuals aged $38-45$ years. It can be assumed this difference to be a result of a longer history of unsuccessful efforts to quit their addiction among the older population, which may have affected their treatment motivation negatively. It is known that substance use behavior in young adults is high, early substance use continues at a later age and gives rise to a number of problems such as educational difficulties, unemployment, poverty, crime, family problems, and so on (23,31-33). Thus, it can be argued that individuals who have to cope with problems caused by early substance use are more aware of the necessity to quit, which may increase their treatment adherence and motivation. In the light of these results, it can be suggested that the identification of the problems causing substance use and the processing of these problems in rehabilitation programs as motivational factor and ambivalence are necessary.

In this study it is found that a higher treatment motivation among persons with a monthly income below $1.000 \mathrm{TL}$ compared to those with an income between 2.800 and $3.700 \mathrm{TL}$. While there is no clear information in the literature about the direction of the relation between income level and substance use, it has been said that substance use behavior is correlated with poverty and the rate of substance use among poor people is higher (34). Even if the personal income may not be a critical factor for treatment adherence or help-seeking, some studies indicate that the opportunities for persons with a low income to benefit from treatment options are small and their perceived need for treatment greater accordingly $(35,36)$. It is also assumed that while for the participants in the study has limited free access to other health and psychosocial services, the fact that they had the opportunity to benefit from free psychosocial and health interventions through probation services may have increased their therapy adherence and motivation. This suggests the necessity to facilitate the access to treatment and psychosocial rehabilitation for substance users with low income, increasing health service options for the use of these individuals, and offer poor people easier access to psychosocial rehabilitation systems by employing the necessary staff.

In this study, it is found that a higher treatment motivation in substance users using more than one substance as well as among those who had been using drugs for more than two years. The change of substance use behavior is a relatively complex process. The number of substances used and the duration of substance use are critical variables for quitting the drug (37). Duration of use and number of substances are a 
risk factor in the development of addiction (38). There is no doubt that addiction carries with it a number of biopsychosocial problems. One of the most important issues resides in the criminal justice system. A drug user is somehow involved in crime, or drug use itself may constitute criminal behavior (39). Being drawn into the legal system may conceivably increase the subject's external motivation to quit the use and thus their treatment adherence and motivation.

Substance use behavior mostly comes with a psychiatric comorbidity (40), or individuals with a psychiatric disorder may later on develop substance use behavior (31). Studies show that persons with psychiatric comorbidity show greater adherence with substance use treatment and have higher internal motivation (17). A similar study carried out by Hiller et al. (41) with criminal addicts found that users with a high level of anxiety and depression symptoms had high internal motivation and displayed more pronounced therapeutic help-seeking behavior. The results also support the outcomes of earlier studies: Substance users with another psychiatric diagnosis had a higher treatment motivation than substance users who had not been previously received a diagnosis. Doubtless, substance use going along with psychiatric problems carries additional biopsychosocial problems for the individual. We can consider additional legal liability of having been sentenced for drug use as an external pushing force for the individual's treatment adherence and motivation.

The data for this study have been collected in a single session in just one probation directorate. Thus, situational, temporal and procedural factors that might affect treatment motivastion could not be determined. As this was a cross-sectional study, the cause-effect relation between the variables could not be established. Therefore, it is sugegsted that it will be necessary to undertake future experimental studies to work out the causality principle. Another limitation lies in the fact that the substance users were referred to the probation directorate through the legal system. This represents a merely external factor that might reduce their internal motivation. Therefore, it is necessary to collect data in a clinical setting with different sample groups. Finally, there are some missing values for sociodemographic and clinical variables, which must be taken in to consideration when evaluating the results.

In this study, it is categorized the intervals for variables such as age and monthly income randomly. Thus, it is hard to say exactly at which developmental stage and in what income bracket treatment motivation is higher or lower. Therefore, longitudinal studies are needed to analyze the relationship between treatment motivation and age. Future studies focusing on the relation between income level and treatment motivation are also needed. Finally, as the number of female participants in the program was insufficient, the study was only performed with male addicts. Thus, possible differences between the genders could not be revealed. Thus, future studies include female substance users should be performed to assess gender-spesific variables and affect of the gender factor on treatmet motivation.

\begin{tabular}{|c|c|c|}
\hline \multicolumn{2}{|c|}{ Contribution Categories } & \multirow{2}{*}{$\begin{array}{l}\text { Author Initials } \\
\text { T.G. }\end{array}$} \\
\hline \multirow{3}{*}{ Category 1} & Concept/Design & \\
\hline & Data acquisition & T.G. \\
\hline & Data analysis/Interpretation & T.G. \\
\hline \multirow{2}{*}{ Category 2} & Drafting manuscript & T.G. \\
\hline & Critical revision of manuscript & T.G. \\
\hline Category 3 & Final approval and accountability & T.G. \\
\hline \multirow{2}{*}{ Other } & Technical or material support & T.G. \\
\hline & Supervision & T.G. \\
\hline
\end{tabular}

Acknowledgements: For his contribution to preparing the table legends and his valuable feedback, I wish to thank my dear friend and valued academic, lecturer Dr. Melik Ertugrul, and I am also grateful to my dear student and intern Cem Demir for his help with data collection.

Ethics Committee Approval: Approval for the study was obtained from Hacettepe University Ethics Committee.

Informed Consent: Written informed consent was obtained from the patient for the publication of the case report.

Peer-review: Externally peer-reviewed.

Conflict of Interest: No conflict of interest.

\section{REFERENCES}

1. UNODC. World Drug Report 2004. Vol 1. Vienna: United Nations Publications, 2004.

2. Burns L. World Drug Report 2013 By United Nations Office on Drugs and Crime New York: United Nations, 2013. Drug and Alcohol Review 2014; 33:216.

3. Sher KJ, Bartholow BD, Wood MD. Personality and substance use disorders: a prospective study. J Consult Clin Psychol 2000; 68:818-829.

4. Vijayakumar L, Kumar MS, Vijayakumar V. Substance use and suicide. Curr Opin Psychiatry 2011; 24:197-202.

5. Whiteford HA, Ferrari AJ, Degenhardt L, Feigin V, Vos T. The global burden of mental, neurological and substance use disorders: an analysis from the Global Burden of Disease Study 2010. PloS One 2015; 10:e0116820. 
6. Rollnick S, Miller WR. What is motivational interviewing? Behav Cogn Psychother 1995; 23:325-334.

7. Jensen CD, Cushing CC, Aylward BS, Craig JT, Sorell DM, Steele RG. Effectiveness of motivational interviewing interventions for adolescent substance use behavior change: a meta-analytic review. J Consult Clin Psychol 2011; 79:433-440.

8. Miller WR, Rollnick S. Motivational Interviewing: Helping People Change. Karadag F, Ogel K, Tezcan AE (Translation Editors) Ankara: Hekimler Yayin Birligi, 2009. (Turkish)

9. Bandura A. Self-efficacy: In Ramachaudran V.S. (editor). Encyclopedia of Human Behavior. Vol. 4. New York: Academic Press, 1994, 71-81.

10. Maisto SA, Connors GJ, Zywiak WH. Alcohol treatment changes in coping skills, self-efficacy, and levels of alcohol use and related problems 1 year following treatment initiation. Psychol Addict Behav 2000; 14:257-266.

11. Dolan SL, Martin RA, Rohsenow DJ. Self-efficacy for cocaine abstinence: pretreatment correlates and relationship to outcomes. Addict Behav 2008; 33:675-688.

12. Kadden RM, Litt MD. The role of self-efficacy in the treatment of substance use disorders. Addict Behav 2011; 36:1120-1126.

13. Stephens RS, Roffman RA, Simpson EE. Treating adult marijuana dependence: a test of the relapse prevention model. J Consult Clin Psychol 1994; 62:92-99.

14. Budney AJ, Higgins ST, Radonovich KJ, Novy PL. Adding voucher-based incentives to coping skills and motivational enhancement improves outcomes during treatment for marijuana dependence. J Consult Psychol 2000; 68:1051-1061.

15. Bowen S, Witkiewitz K, Clifasefi SL, Grow J, Chawla N, Hsu SH, Carroll HA, Harrop E, Collins SE, Lustyk MK, Larimer ME. Relative efficacy of mindfulness-based relapse prevention, standard relapse prevention, and treatment as usual for substance use disorders: a randomized clinical trial. JAMA Psychiatry 2014; 71:547-556.

16. Ogel K, Koc C, Aksoy A, Basabak A, Evren C. Cigarette, Alcohol and Drug Addiction Treatment Program (SAMBA). Yeniden Yayinlari, Istanbul, 2012.

17. Ryan RM, Plant RW, O’Malley S. Initial motivations for alcohol treatment: relations with patient characteristics, treatment involvement, and dropout. Addict Behav 1995; 20:279-297.

18. Evren C, Saatcioglu O, Dalbudak E, Danismant BS, Cakmak D, Ryan RM. Factorial Structure and Reliability and Validity of Turkish Version Treatment Motivation Questionnaire (TMQ) in Alcohol Dependents. Journal of Dependence 2006; 7:117-122. (Turkish)

19. Sherer M, Maddux JE, Mercandante B, Prentice-Dunn S, Jacobs B, Rogers RW. The self-efficacy scale: construction and validation. Psychological Reports 1982; 51:663-671.

20. Magaletta PR, Oliver JM. The hope construct, will, and ways: their relations with self-efficacy, optimism, and general wellbeing. J Clin Psychol 1999; 55:539-551.

21. Yildirim F, Ilhan IO. The Validity and Reliability of the General Self-Effi cacy Scale-Turkish Form. Turk Psikiyatri Derg 2010; 21:301-308. (Turkish)
22. Carver CS, Scheier MF, Weintraub JK. Assessing coping strategies: a theoretically based approach. J Pers Soc Psychol 1989; 56:267-283.

23. Carver CS. You want to measure coping but your protocol's too long: Consider the brief cope. Int J Behav Med 1997; 4:92-100.

24. Tuna ME. Cross-cultural differences in coping strategies as predictors of university adjustment of Turkish and US students. Doctoral Thesis, Middle East Technical University, Ankara, 2003.

25. DiClemente CC, Bellino LE, Neavins TM. Motivation for change and alcoholism treatment. Alcohol Res Health 1999; 23:86-92.

26. Prochaska JO, DiClemente CC, Norcross JC. In search of how people change: Applications to addictive behaviors. Am Psychol 1992; 47:1102-1114.

27. Wild TC, Cunningham JA, Ryan RM. Social pressure, coercion, and client engagement at treatment entry: a self-determination theory perspective. Addict Behav 2006; 31:1858-1872.

28. Miller WR, Tonigan JS. Assessing drinkers' motivation for change: the Stages of Change Readiness and Treatment Eagerness Scale (SOCRATES). Psychol Addict Behav 1996; 10:81-89.

29. Galea S, Nandi A, Vlahov D. The social epidemiology of substance use. Epidemiol Rev 2004; 26:36-52.

30. Inskip HM, Harris EC, Barraclough B. Lifetime risk of suicide for affective disorder, alcoholism and schizophrenia. Br J Psychiatry 1998; 172:35-37.

31. Brook JS, Cohen P, Brook DW. Longitudinal study of co-occurring psychiatric disorders and substance use. J Am Acad Child Adolesc Psychiatry 1998; 37:322-330.

32. Khan MR, Golin CE, Friedman SR, Scheidell JD, Adimora AA, Judon-Monk S, Hobbs MM, Dockery G, Griffin S, Oza KK, Myers D, Hu H, Medina KP, Wohl DA. STI/HIV sexual risk behavior and prevalent STI among incarcerated African American men in committed partnerships: the significance of poverty, mood disorders, and substance use. AIDS Behav 2015; 19:1478-1490.

33. Mun CJ, Dishion TJ, Tein JY, Otten R. Adolescence effortful control as a mediator between family ecology and problematic substance use in early adulthood: a 16-year prospective study. Dev Psychopathol 2018; 30:1355-1369.

34. Thompson RG, Alonzo D, Hu MC, Hasin DS. Substance use disorders and poverty as prospective predictors of adult firsttime suicide ideation or attempt in the United States. Community Ment Health J 2017; 53:324-333.

35. Rosen D, Tolman RM, Warner LA. Low-income women's use of substance abuse and mental health services. J Health Care Poor Underserved 2004; 15:206-219.

36. Patel V, Araya R, Chatterjee S, Chisholm D, Cohen A, De Silva M, Hosman C, McGuire H, Rojas G, van Ommeren M. Treatment and prevention of mental disorders in low-income and middleincome countries. Lancet 2007; 370:991-1005.

37. DiClemente CC. Motivation for change: implications for substance abuse treatment. Psychol Sci 1999; 10:209-213.

38. Tucker JS, Ellickson PL, Orlando M, Martino SC, Klein DJ. Substance use trajectories from early adolescence to emerging adulthood: a comparison of smoking, binge drinking, and marijuana use. J Drug Issues 2005; 35:307-332. 
39. UNODC. World Drug Report 2012. Vienna: United Nations Office On Drugs And Crime, 2012. http://www.unodc.org/ unodc/en/data-and-analysis/WDR-2012.html. Accessed May 26, 2018.

40. Szoke A, Galliot AM, Richard JR, Ferchiou A, Baudin G, Leboyer M, Schurhoff F. Association between cannabis use and schizotypal dimensions - a meta-analysis of cross-sectional studies. Psychiatry Res 2014; 219:58-66.

41. Hiller ML, Narevic E, Webster JM, Rosen P, Staton M, Leukefeld C, Garrity TF, Kayo R. Problem severity and motivation for treatment in incarcerated substance abusers. Subst Use Misuse 2009; 44:28-41. 